\title{
Jacob Thaisen*
}

\section{Secretary letter-shapes in County Durham}

https://doi.org/10.1515/flih-2017-0009

Abstract: This paper applies quantitative methods in palaeography. It develops tree-structured regression models of the palaeographical variation found in a synchronic corpus of texts written in orthographically less standardised late Middle English and establishes their accuracy. There are sixteen models, each one relating to a letter-shape known to distinguish the Gothic cursive scripts Anglicana and Secretary. The models predict the presence of the individual letter-shape from one or more of the following variables, in no particular order: (1) localisation of texts' orthographic variation; (2) text-type; and (3) in-word position. The discussion asks why several Secretary letter-shapes cluster in documents localisable to County Durham and the area further north, given the script's association with (a) institutions of national administration in the London-Westminster area and (b) orthographic standardisation. It concludes that the linguistics and the palaeography do not co-vary during this period in the history of the English language and suggests that it may illuminate studies of the gradient between Anglicana and Secretary to pay attention to provincial centres, not least Durham.

Keywords: regression modelling, Middle English, Gothic cursive script, orthographic standardisation

\section{Introduction}

The adjective "quantitative" tends to be used loosely as a descriptive label in palaeography. From the field once, famously, being lamented as an exclusively qualitative one, “an art of seeing and comprehending” (Bischoff 1979[1990]: $3),{ }^{1}$ recent work manifests an increased interest in quantification. An atypical example of such recent work, the Mediaeval Palaeographical Scale, is a regression

1 The full citation is "Tools are being created which will provide palaeographers with reliable assistance and ease their work. With the aid of technological advances palaeography, which is an art of seeing and comprehending, is in the process of becoming an art of measurement" (Bischoff 1979[1990]: 3; cf. Derolez 2003: 1-27).

*Corresponding author: Jacob Thaisen, Department of Literature, Area Studies and European Languages, University of Oslo, P.O. Box 1003 Blindern, 0315 Oslo, Norway

E-mail: jacob.thaisen@ilos.uio.no 
model trained on data collected from an unpublished corpus of mediaeval documents written in Dutch. ${ }^{2}$ The variables are letter-shapes along with the date and place of production of the documents in which they occur. The model estimates the relationships among these variables.

What is atypical about the Scale is that it is both the data and their analysis (the model) which are quantitative. What is typical rather is for the data to be quantitative but for their analysis to be visual. An example would be a study such as Kwakkel's (2012) of the transition from Carolingian to Gothic script whose analysis consists in the scholar visually identifying a correlation based on a graphical representation of quantitative data, say a line graph giving the percentage of texts which meet some criterion by time or a stacked bar chart giving the collected occurrence of certain features by text. Studies of this kind may fall short of the mark, in that they may not consider any possible collinearity or interaction among the variables, nor address whether the analysis underfits or overfits the data. A range of statistical tools are available for testing such properties.

The present paper too is of the atypical kind. It builds tree-structured regression models of the relationships among variables relating to texts' localisation, their text-type, and the in-word position of the individual letter-shapes. This analysis shows each letter-shape to be predicted by one or more of the variables, which suggests a division of labour between diffusion mechanisms and an own history for each letter-shape. Much scholarship on Secretary script has debated the locus of its first arrival to England rather than its later diffusion. It has traditionally been associated with royal clerks at Westminster, but Westminster is perhaps to be understood in a figurative sense as the institutions of England's government rather than a strictly geographical one. What is more, Secretary script certainly diffused beyond the London-Westminster area with time, and the principal finding reported in this paper is that several shapes diagnostic of it cluster in documents localisable to County Durham and the area further north.

To underpin the diffusion from the London-Westminster area to the Far North indicated by the quantitative analysis, the paper is structured as follows. The next section details the data and the corpus from which they were collected, and it justifies the selection of variables. A section introducing the modelling methodology follows and leads on to a description of the results, which the discussion then contextualises and evaluates. It also gives the models' accuracy in tabular form and discusses it. The conclusion summarises.

2 The Scale is described in Burgers 2007; He et al. 2014; and Samara 2015. 


\section{Corpus and variables}

The Middle English Grammar Corpus [MEG-C] enables a synchronic survey of what letter-shapes occur in localised texts. The corpus samples the population of texts written in English and in less standardised orthography within the period c. 1350-1450 and totals 449 texts. $^{3}$ The actual place of production in geographical terms is unknown for the majority of the texts included in MEG-C but their less standardised orthography enabled their localisation in eastings and northings for the purposes of “A Linguistic Atlas of Late Mediaeval English” [LALME] (McIntosh et al. 1986); that is, every text was situated in a two-dimensional space based on the similarity of its orthography with the orthography found in other texts. Localisation thus represents a plane of fit, possibly a plane of best fit. The regression models built in what follows treat a text's respective localisation in eastings and northings as separate variables and confirm the predictorhood of both.

There are sixteen separate models, corresponding to the sixteen separate letter-shapes shown in Table 1. In order for me to be able to harvest tokens of these letter-shapes, I obtained a photographic reproduction of at least one page

Table 1: Sixteen letter-shapes.

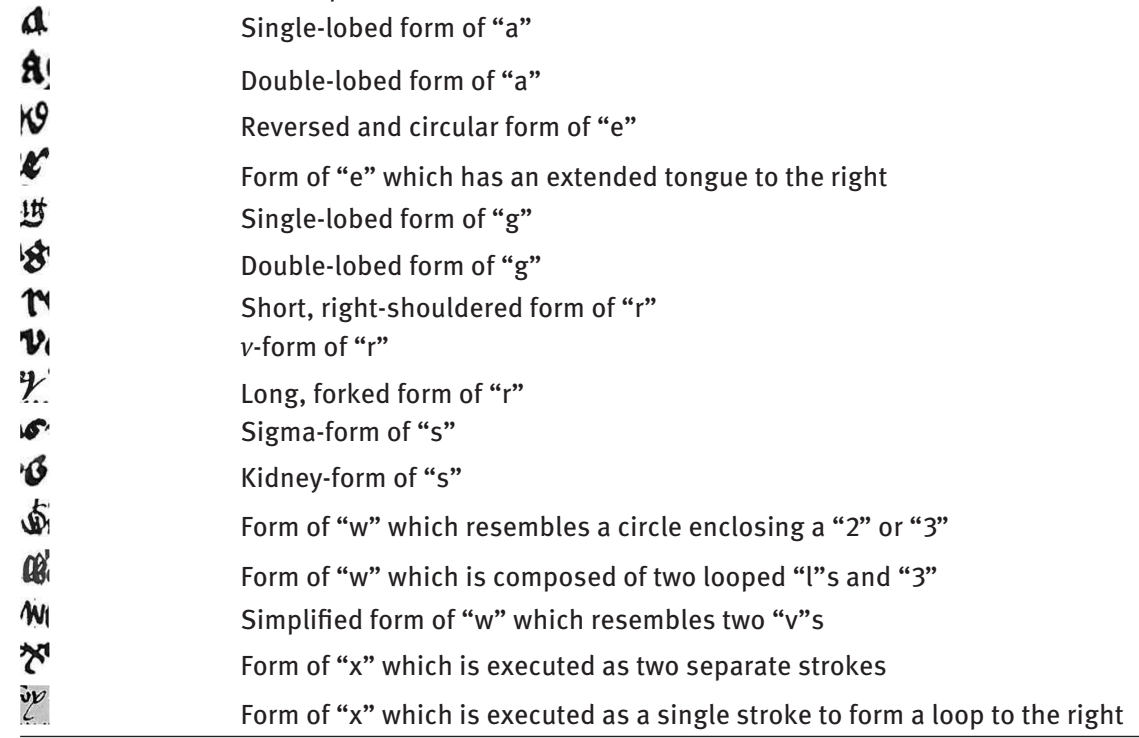

3 Transcriptions are downloadable from the University of Stavanger: http: //www. uis. no/mest. The latest published version, 2011.1, contains 410 of the present texts. 
from every text included in MEG-C courtesy of the Middle English Scribal Texts programme at the University of Stavanger.

I harvested 6,570 tokens of the sixteen letter-shapes from the 449 texts. In examining a given text, I paid no attention to the proportion of tokens of one letter-shape to another within that text or to small variations in execution, focussing instead on the presence or absence of what Parkes (2008: 152) calls the letter-shape's "essential elements" in the given token. ${ }^{4}$ I did not record any emphatic token unless it differed from non-emphatic tokens of the same lettershape exclusively by size, nor any superscripted token regardless of any possible resemblance of it with non-superscripted tokens, nor any token representing a numeral. The photographic reproduction sometimes rendered an unambiguous classification of a token uncertain, and at other times the composition of the token itself fell somewhere in between two letter-shapes. I left out of consideration any such token that could not be readily classified.

In contrast, I took into consideration whether the given token occurred in initial, medial, or final position in the word, thus collecting a maximum of three tokens of any given letter-shape per text. ${ }^{5}$ I did so exclusively with regard to the horizontal dimension, although it is a characteristic of the mediaeval English writing system that the direction of writing shifts from horizontal to vertical for marks such as the bar which may or may not always have any linguistic function.

A second, two-dimensional variable crudely captures text-type, the dimensions being literary form (prose vs. verse) and format (document vs. nondocument). There are no documentary texts in verse in the corpus but there are non-documentary prose texts. Prose and verse are both understood as descriptors applying to running text, so that an account (in the bookkeeping sense) or an index is neither. ${ }^{6}$ A cartulary copy of a document does not have the physical format of a document and is tagged accordingly.

Text-type is again a variable well-acknowledged as a predictor in the palaeographical literature; witness standard labels like "court hand" and "book hand". Doyle has argued for the professional network as a chief diffusion mechanism for palaeographical styles in the period under investigation, leading to their "quite rapid national dissemination" (1994: 95; emphasis original), and there exists the tangible evidence of London scribes being specialised according to text-type that separate guilds formed for "Writers of the Text Letter" (non-documents) and "Writers of the Court Letter" (documents) some time after 1373.

\footnotetext{
4 Parkes (2008: 152): "those characteristics of a letter shape, which enable a reader to distinguish one letter from another."

5 I ignored tokens of the letter "a" found in isolated position (as the indefinite article).

6 Spatial constraints may possibly affect a scribe's selection of letter-shape. Similar spatial constraints apply to all text laid out in columns, be it an index or end-rhymed verse. Fitting running prose within a ruled frame is another matter.
} 
On the other hand, it was in this same period that clerks and notaries began to copy out literary texts for inclusion in codices, not least to satisfy their own reading interests (Parkes 1973; Clanchy 2013); and wills and ownership marks studied by Friedman (1995) suggest a tradition of seeking in-situ expertise for any writing task existed in the provinces, whether preparation of documents or copying of literary works. ${ }^{7}$ It is certainly plausible for letter-shapes characteristic of one texttype to have diffused to another in these circumstances. However, the regression models show that the shapes have not diffused so widely as to present a challenge to the predictorhood of the text-type variable in a synchronic analysis. The models also gauge its effect.

The palaeographical literature acknowledges in-word position as a predictor. It does so inasmuch as some letter-shapes are bound to certain positions by lexis (the letter "a" rarely occurs in final position) or by basic ductus (the form of " $e$ " which has an extended tongue to the right is exclusively word-final; the sigma-form of "s" tends not to precede an ascender). The variable is the final one considered in this paper, and the regression models verify its predictorhood in relation to these known, trivial cases but it also puts into focus other cases of patterned variation that are less trivial, such as a leftward movement of the reversed and circular form of " $e$ " (see below). Note, however, that the variable is not this paper's central concern. It is included in the models for the sake of completion and raises their accuracy to a level where many of them can be expected to generalise. Distinguishing three levels for in-word position as a variable was a compromise: although ease-of-juncture is not orthogonal on in-word position and may be the stronger predictor, it was not practicably possible to record what letter-shape respectively precedes and follows every token, let alone record every token of every letter-shape in every text.

\section{Methodology}

My modelling methodology is the conditional inference tree (Hothorn et al. 2006). This methodology, implemented in the partykit package for the $\mathrm{R}$ software environment for statistical computing (Hothorn and Zeileis 2015), is a close rel-

7 "It is certainly clear from our study that Norton, Hawke, Est, Anlaby, Wolveden, and others like them [ecclesiastical bureaucrats] preferred to make their own books or to seek scribes among priests, notaries, chaplains or local semiprofessionals rather than to have books commissioned in the south or on the Continent”, writes Friedman (1995: 30) about the north of England. As will become apparent, the palaeographical conservatism that would follow from reliance on in-situ expertise in provincial areas is more strongly evidence between the Midlands line and the North Riding/County Durham line than it is above it. 
ative of the decision tree designed to avoid overfitting a model to its training data. The principal difference is that the conditional inference tree uses non-parametric significance testing to select predictors from among the variables rather than maximisation of information gain. Like all tree-structured models, conditional inference trees outperform linear or logistic models by being a methodology able to handle continuous and categorical variables simultaneously. Moreover, a conditional inference tree's accuracy is always optimum given the variables, since the significance testing behind it "ensures that the right-sized tree is grown without additional (post-)pruning or cross-validation" (Hothorn and Zeileis 2015: 8). A model which has an accuracy of above 80 percent is likely successfully to generalise to the population from which the training data were extracted, while a lower accuracy means it accounts for the training data only. The present trees correctly predict between 60 and 85 percent of the training data.

The methodology produces a model which may be visualised as an upsidedown tree with nodes which always fork into exactly two branches. Every such fork represents a partitioning of the training data into two maximally homogeneous sets based on the values of continuous variables and levels of categorical variables. The variable associated with a node is the variable with the strongest statistically significant association with the two sets formed at that node, which makes it a predictor. Partitioning of sets into still smaller sets proceeds recursively in descending order of predictor strength until statistical significance is exhausted. It can be seen that predictor selection is robust against outliers in the training data and immune to collinearity among the variables.

\section{Results}

I grew a separate conditional inference tree for each of the sixteen letter-shapes. ${ }^{8}$ Of these, Figure 1 gives the tree grown for the reversed and circular form of " $\mathrm{e}$ " as an illustration, whereas the rest are not shown. It can be seen from the tree that localisation in northings (nodes 3 and 6), text-type (node 1), and in-word position (nodes 2, 7, 11, and 12) all appear among the predictors of the reversed and circular form of " $\mathrm{e}$ " while localisation in eastings does not. It can also be seen that text-type is the strongest of the predictors, being the highest node, and that the letter-shape is variously associated with localisations above c. 300 northings, documents, and non-initial position.

8 At four tokens, observations of a seventeenth shape, the form of " $\mathrm{x}$ " which is executed as a single stroke to form a loop to the right, are too few for meaningful analysis. 


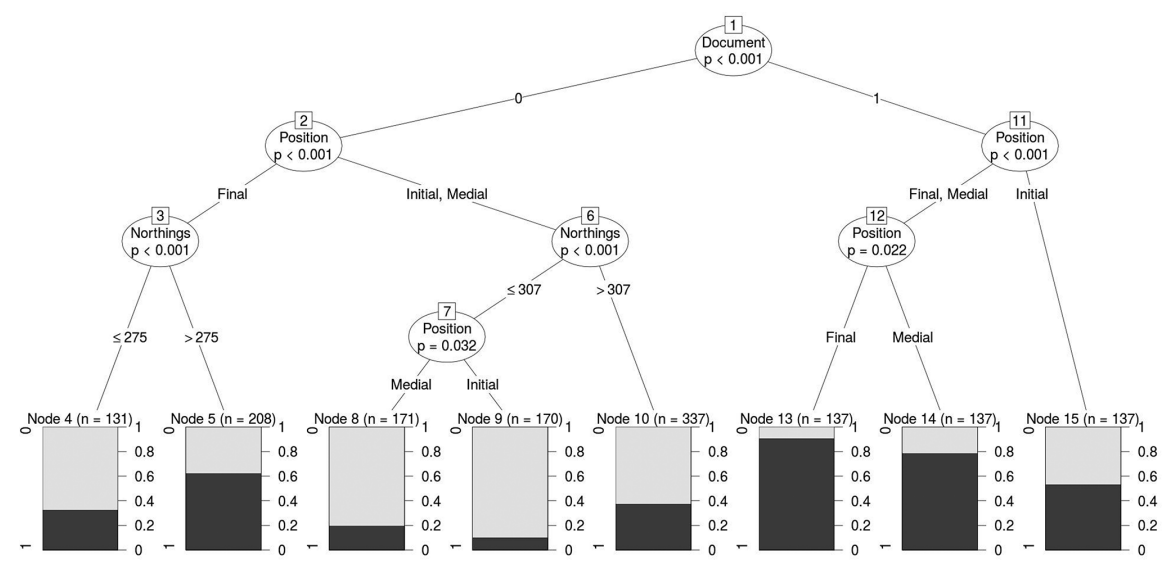

Figure 1: Conditional inference tree estimates of the relationship between predictors of the reversed and circular form of "e".

Note: The boxed number which appears above the name of a predictor at a node is an identifier, and the $p$ value below it expresses the significance level for the partitioning of the training data at the given node. The values or levels at which the training data are partitioned are given along the edges, while an edge's length is immaterial. The $n$ value which appears by a terminal node gives the number of observations in the training data conforming to the particular configuration of the predictors. A bar chart's left-hand scale gives levels of the response, in this case the presence or absence of the given letter-shape. A bar chart's right-hand scale gives the proportion of observations for each level according to the training data.

The dialectologist's isogloss bundle is a relevant concept in explaining what the trees reveal about localisation in northings as a predictor. This is because several trees partition the training data at two sets of highly similar values for this predictor at the same time as the trees for no two letter-shapes are identical. Moreover, there is no partitioning of the training data according to this predictor which falls outside of the two sets. The first set centres on c. 500 northings, which would align with the border between the North Riding of Yorkshire and County Durham in geographical terms. Above this value, the single-lobed form of " $g$ ", the simplified form of "w" which resembles two "v"s, the single-lobed form of "a", and the form of " $\mathrm{x}$ " which is executed as a single stroke to form a loop to the right-all letter-shapes associated with Secretary-are observed in higher proportions in the relevant configurations of the predictors relative to below the line, while the double-lobed form of " $a$ " and the form of " $x$ " which is executed as two separate strokes-both letter-shapes associated with Anglicana-are observed in relatively lower proportions. 
The second set relates to c. 300 northings, which would correspond to a line running across the Midlands from Birmingham to south of Norwich in geographical terms. Above this value, the long, forked form of " $r$ ", the reversed and circular form of "e", and the sigma-form of "s"-all letter-shapes associated with Anglicana-are observed in higher proportions in the relevant configurations of the predictors relative to below the line, while the single-lobed form of " $\mathrm{g}$ ", the short, right-shouldered form of " $r$ ", and the single-lobed form of "a"-all letter-shapes associated with Secretary-are observed in relatively lower proportions.

The dialectologist's isogloss bundle is, by contrast, not a relevant concept when it comes to explaining what the trees reveal about localisation in eastings as a possible predictor. The evidence for this finding is that only two of the mere four trees which include this predictor meet the criterion of partitioning the training data at roughly the same value. ${ }^{9}$

The trees confirm that text-type is a predictor. It is one relevant to as many as twelve of the sixteen letter-shapes, and format (documents vs. non-document) is a stronger text-type predictor than literary form (prose vs. verse). The evidence for the latter finding is that format is a predictor of several more letter-shapes (ten) than literary form (four), and is always a higher node in trees in which both appear (two). When a predictor is a higher node, it is difficult to isolate its effect, since it has an additive effect together with lower ones. With this proviso, it is possible to generalise about format that a text's being a document has the effect that it decreases the observations of the form of " $w$ " which is composed of two looped "l"s and " 3 " and the form of "e" which has an extended tongue to the right, whereas it increases those of the reversed and circular form of " $e$ " and the sigma-form of " $\mathrm{s}$ " in most configurations. Regarding literary form, a text's being in verse has the effect of increasing the observations of the form of "w" which resembles a circle enclosing a "2" or " 3 ", and those of the double-lobed figure 8 form of " $g$ " in initial and medial positions increase if the text is not in prose.

In-word position too is an important predictor of the presence or absence of a letter-shape in a text. This is apparent, since as many as thirteen of the sixteen conditional inference trees include this predictor and since it appears as the highest node in as many as ten of them. One case merits explicit comment. The reversed and circular form of "e" tends within each branch of its tree to have its highest proportions of observations in final position, lower ones in medial position, and lower ones still in initial position. This distribution is consistent with

9 The long, forked form of "r" is observed in relatively lower proportions and the single-lobed form of "g" in relatively higher proportions below c. 620 eastings, which corresponds to Norwich in geographical terms. 
diffusion of the letter-shape over time from final position to in-word positions where it was not previously found, which is what Parkes (2008: 133) has proposed for it on the basis of qualitative analysis.

\section{Discussion}

The non-coincidence of the trees shows that every letter-shape has its own history, to paraphrase the familiar observation, usually attributed to Gilliéron, about dialectal variation in French at the turn of the nineteenth century into the twentieth. This finding, in turn, confirms that Secretary cannot have diffused as a whole after its first arrival to England. ${ }^{10}$ Unlike Anglicana, which does not have a foreign source, Secretary is modelled on contemporary French chancellorial script. It is commonly accepted that its adoption can be dated to the final third of the fourteenth century and involves royal clerks at Westminster.

However, inexact definitions mar the discussion and has led to misclassification such as that by Fisher et al. (1984) discussed by Matheson (1986), Takeda (2001), and Benskin (2004). The literature does not define Anglicana or Secretary as any particular combination of letter-shapes, all of which must be present in a text to justify its classification as one or the other. Instead it exemplifies lettershapes diagnostic of each script while acknowledging (a) that not every shape diagnostic of a script has to be present in a text to warrant its classification as being written in that script; and (b) that shapes diagnostic of both Anglicana and Secretary are commonly present in varying proportions alongside each other in actual texts written in English in late mediaeval England. ${ }^{11}$

The literature is similarly vague about criteria for situating such hybrids on a gradient from the one script to the other. Roberts explains that "[o]ften it is hard to decide binarily between an Anglicana and a Secretary definition [...] sometimes the mix of diagnostic letter-forms is so evenly balanced as to make it necessary to count their relative frequencies" (2005: 161-162; cf. Petti 1977: 15). However, counting relative frequencies is a terrible criterion: It risks assigning opposite class membership to near-identical samples, erroneously assumes of all lettershapes that they are independent classifiers of equal weight, and denies the possible non-binary division of the gradient between Anglicana and Secretary. The absence of a clear definition renders it unclear whether the royal clerks who

10 Chaplais suggests the intentional adoption of Secretary letter-shapes, referring to the script as "the result of a break-away from English writing traditions rather than the outcome of a gradual evolution” (1971: 52).

11 See, for example, Parkes 2008: 113-115. 
first developed Secretary on the French model did so by piecemeal or wholesale adoption of letter-shapes.

These royal clerks themselves constitute a further point of unclarity. Petti (1977: 14) portrays "Chancery warrants" dating from the 1370 s as early examples of English-language texts written in Secretary but in Parkes (1969: xix-xxi), perhaps Petti's source, the term "Chancery" refers to the writing office of the Archbishop of Canterbury at Lambeth Palace (cf. Hanna 2005: 226), and it has become clear in the last two decades that if royal clerks were instrumental in diffusing Secretary letter-shapes at all, then they were the handful of clerks attached to the Privy Seal and Signet Offices rather than the numerous ones attached to Chancery who, in addition to being a much larger group, constituted a changeable one, as Chancery recruited supplementary temporary staff on an as-needed basis. In fact, "[i]n the collection of Chancery Warrants issued under the Privy Seal or Signet the new script [that is, Secretary] is first used extensively in 1376, but it is hardly ever used in the other offices of the central government" (Parkes 1969: xx, cf. 2008: 113), and Chancery may have been "a slow recipient [of Secretary lettershapes], not an initiator of their use[, i]f royal clerks were responsible for their dissemination at all” (Benskin 2004: 13; cf. Benskin 1992; Chaplais 1971: 52).

Moreover, when royal clerks were engaged in professional activities, they may have been so in the general London-Westminster area as opposed to specifically at Westminster. Dodd's (2011b: 244, cf. 2011a: 121) distinction between "the clerks and scribes who inhabited the writing offices of Westminster" and "their freelance colleagues based in London" echoes older scholarship, whereas the newer view is that "[r]oyal clerks were ubiquitous in London" (Richardson 2011: 49). Many of them lodged with London landlords and were engaged in business for the city and for merchants based in it as well as for the institutions of national government. Consider the Privy Seal clerk (and poet) Thomas Hoccleve, who wrote a Secretary hand. His office, which doubled as his living quarters, was up until his marriage not at Westminster at all but at an Inn of Chancery (Chester Inn), which was located on the Strand and was attached to a neighbouring Inn of Court (Middle Temple), itself adjacent to another Inn of Court (Inner Temple). With these inns in the immediate vicinity, it is hard to imagine Hoccleve not encountering other clerks employed by other offices in his daily life, let alone materials penned by them, and vice versa. ${ }^{12}$ It seems possible against this background to understand royal clerks in a broader geographical sense and with it, Secretary as encapsulating tendencies simultaneously manifest in multiple writing centres within the

12 Thompson (2000) offers a number of examples of such other clerks Hoccleve encountered or may have encountered, and Mooney (2008) discusses a web of connections between clerks active in the London-Westminster area. 
London-Westminster area, certainly in relation to its diffusion and possibly even in relation to its first arrival.

The performing of duties elsewhere extended to the provinces and even abroad. An early example of an Englishman using Secretary script is thus a Privy Seal clerk preparing a document for Edward the Black Prince in Gascony in 1370 (Chaplais 1971: 52; Hanna 2005: 226; Benskin 2004; Parkes 2008: 113, n. 56). The clerk in question, John Fordham, was promoted to Keeper of the Privy Seal in 1376 and Lord Privy Seal in 1377. He became Bishop of Durham four years later and resigned this post in 1388 in favour of the See of Ely. Fordham's geographical movements suggest how Secretary letter-shapes may plausibly have diffused through a clerk's agency and at an early date too. They may have diffused hierarchically between writing centres as opposed to geographically contiguously, which would mean text-type was a stronger predictor than localisation.

Fordham's geographical movements were by no means unique for a clerk. Another clerk as senior as him, Walter Skirlaw, started out as an official of the Court of York (1374), then served as a Chancery clerk (1377) and rose to Keeper of the Privy Seal (1382), before eventually being appointed Bishop of Durham (1388), replacing Fordham. It was even possible for a clerk to hold simultaneous positions in the provinces and in the London-Westminster area. Robert Rolleston thus served as Provost of Beverley Minster (1427-1450) and was simultaneously Keeper of the Great Wardrobe (1418-1444), and another provost of the same minster (1381-1419), Robert de Manfield, was simultaneously keeper of writs and rolls for the Court of Common Pleas (1397-1410) (McDermid 1980).

The palaeographical developments weakly correlate with orthographic standardisation in respect of chronology and geography, ${ }^{13}$ and scholarly arguments over what exact location within London-Westminster led the way follow similar lines. Fisher (1979: 136) applied contemporary ideas about language planning to the mediaeval situation and concluded that "the standardisation of modern English was a by-product of the standardisation of administrative procedures by the clerks of Chancery in the fifteenth century. It is probable that standard languages have always been formed in this way".

There is no disputing the pivotal role of documents and the clerks who produced, received, and processed them in what was not only the nation's administrative centre and the seat of its government but also a hub for trade. What has mounted in the last two decades is evidence against the applicability of the language planning model. This evidence disconnects standardisation from Chancery and instead situates it in no single geographical locus within the

13 Fisher et al.'s (1984: 4-5) claim of a strong correlation between orthographic standardisation and a set hand within Chancery has been forcefully rejected by Benskin (2004: 11-14). 
London-Westminster area. One part of the evidence is that Chancery documents do not, in fact, show any unidirectional development toward the variety that has developed into present-day Standard English over time, let alone any sudden, categorical shift indicative of imposition of standardised spelling forms by a regulating body (Benskin 2004). This is to the extent that the clerks wrote in English in the first place, since Latin continued to dominate (Benskin 2004; Dodd 2011a, 2011b), and it is to the extent that the language of a Chancery document is representative, for Chancery not only issued documents and dispatched them to recipients. The institution also received documents produced elsewhere for archiving purposes, which often entailed Chancery clerks copying them (cf. Dodd 2011b). The terms "Chancery Standard” and "Chancery English" are today considered misnomers for the predecessor of present-day Standard English for this reason (cf. Wright 1996; Takeda 2001; Benskin 2004).

The other part of the evidence is that the professional activities of Chancery clerks routinely took place away from Westminster Hall. For example, the Six Clerks' Office, engaged in enrolling and filing cases, was permanently based at an Inn of Court (Lincoln's Inn), which itself neighboured another Inn of Court (Gray's Inn). Both these Inns were, and still are, situated on what is today called Chancery Lane, a location immediately outside the London city wall and some distance from Westminster Hall. Chancery clerks resemble Signet and Privy Seal clerks in this respect, and if Fordham may have diffused Secretary letter-shapes through him geographically relocating, future clerks being trained at the Inns of Court and Chancery may have done so with spelling forms. They may have divided their time between the London-Westminster area and their home counties, simultaneously carrying on their trade in both places and taking spelling forms with them in the process (Benskin 1992; Benskin 2004).

By contrast, some scholarship has linked orthographic standardisation to immigration to the London-Westminster area, ultimately citing Ekwall's (1956) studies of surnames as evidence of the origin of the immigrants. On this evidence, most immigrants originated in the East Midlands, especially East Anglia, up until the mid-fourteenth century after which the composition shifted westward (Samuels 1963). Kristensson (2001: 74-76) describes how they comprised merchants and clerks among the more numerous groups, and how several immigrants rose to prominent positions in their adopted home. Their rise in society, he argues, lent overt prestige to their dialect, which consequently became the target of the adaptive strategies of other speakers.

However, Ekwall's methodology was always to match a toponymic surname with the one among the possible locations in England which was nearest the London-Westminster area, which may have skewed the results in the direction of eastern and central parts of the Midlands. Moreover, the surnames appear in 
tax rolls predating the arrival of Secretary letter-shapes by up to a century, and the present regression analysis has found localisation in eastings to be largely non-significant as a predictor of these shapes.

What the analysis has found is that some Secretary letter-shapes are predicted by localisation in northings and format. The single-lobed form of " $g$ ", the simplified form of "w" which resembles two " $v$ "s, and the form of " $x$ " which is executed as a single stroke to form a loop to the right belong to this set. All three letter-shapes are observed in relatively higher proportions in documents localisable to above the North Riding/County Durham line. The Secretary singlelobed form of "a" is also observed in relatively higher proportions above this line, while its Anglicana counterpart, the double-lobed form of "a”, is observed in relatively lower proportions. These Secretary letter-shapes almost certainly hierarchically diffused from the London-Westminster area through the agency of clerks like Fordham and Skirlaw. They cannot result from geographically contiguous diffusion, since what dominates below the line is letter-shapes associated with Anglicana.

So, there is evidence of a separate tradition having formed in the area above the North Riding/County Durham line. Further study may bring evidence to light to sustain a speculation about this tradition having grown up around the institutions of government for County Durham in much the same way that Secretary diffused within the London-Westminster area. The county, headed by the bishop, enjoyed a considerable degree of autonomy in legislative, judicial, and executive matters as a palatinate, thus processing a considerable volume of documents for local consumption. The institutions governing it were situated in the city of Durham itself and its satellite of Bishop Auckland 12 miles to the southwest, which served as the principal episcopal residence outside the city.

On the other hand, the palatinate was not the sole administrative unit with a special status found in the area above the North Riding/County Durham line. March law applied north of County Durham, with the Bishop of Durham administrating it for the English East March for some of the period under discussion, and the Middle and West Marches being under the wardenship of magnates like the Percys and the Nevilles. A warden enjoyed regalian prerogatives, since the Marches were legally not a part of the realm of England. Regardless of Durham's exact role, it is no coincidence that the Secretary letter-shapes cluster in an area corresponding to the Marches and the County Palatine of Durham together. This area was by no means one where all legislative, judicial, and executive matters were handled locally but it was one where the sense of regional identity was strong and it was one where the semi-autonomous administrative setup fostered the growth of a separate tradition. 
Unlike the Midlands line, the North Riding/County Durham line is not strongly in evidence at levels of linguistic description such as phonology and lexis. This incongruity indicates that the linguistics and the palaeography at best weakly correlate, which in turn underlines that the diffusion of Secretary script and of standardised orthographic forms are not two sides of the same coin.

Last, Table 2 gives the accuracy of each conditional inference tree as a regression model of the relationships among the predictors of the given letter-shape. The models' accuracy is given as the "C-index" output by the somers 2 function available in the Hmisc package for R, which numerically expresses it as a value between 0 and 1. A model's accuracy is straightforwardly what proportion of the training data it correctly predicts, and it will be recalled that a conditional inference tree's accuracy is always the optimum that can be achieved with the given variables. This means that all variables which a tree determines to be predictors indisputably are predictors of the training data. In addition, the higher the accuracy, the greater is the likelihood that a tree will successfully generalise to the population represented by the training data. The cutoff point is conventionally set at around 80 percent for any regression model, whether tree-based or not.

It can be seen from Table 2 that the trees correctly predict between 60 and 85 percent of the training data. Although these $\mathrm{C}$-indices indicate that not all the trees may be expected successfully to generalise, what the indices indicate

Table 2: Model criticism.

\begin{tabular}{lr}
\hline Letter-shape & Accuracy \\
\hline Single-lobed form of "a" & 0.7977 \\
Double-lobed form of "a" & 0.8491 \\
Reversed and circular form of "e" & 0.7877 \\
Form of "e" which has an extended tongue to the right & 0.8570 \\
Single-lobed form of "g" & 0.6516 \\
Double-lobed form of "g" & 0.6019 \\
Short, right-shouldered form of "r" & 0.6865 \\
-form of "r" & 0.6303 \\
Long, forked form of "r" & 0.6835 \\
Sigma-form of "s" & 0.8553 \\
Kidney-form of "s" & 0.8552 \\
Form of "w" which resembles a circle enclosing a "2" or "3" & 0.7160 \\
Form of "w" which is composed of two looped “l”s and "3" & 0.7298 \\
Simplified form of "w" which resembles two "v"s & 0.6496 \\
Form of "x" which is executed as two separate strokes & 0.6465 \\
Form of "x" which is executed as a single stroke to form a loop to the right & 0.7546 \\
\hline
\end{tabular}


is by no means a poor result but rather a promising one, given the exploratory nature of the research, the low number of variables considered, and the comparatively small size of the data set. To be specific, I posited in-word position as a variable with three levels (initial, medial, and final) but this variable is clearly not orthogonal on another variable and thus potential predictor, ease-of-juncture. Future research may increase the models' accuracy by distinguishing more levels for the position predictor in order to take ease-of-juncture better into account. Other potential improvements are the introduction of a more fine-grained texttype typology and a rejection of texts' LALME localisations in favour of their actual place of production. Finally, there exist further variables deserving to be tested for predictorhood, not least date of production, cursiveness, and available space.

\section{Conclusion}

To sum up, this paper has shown that (1) respective LALME localisation in eastings and northings and (2) text-type in the sense of literary form (prose vs. verse) and format (document vs. non-document) are predictors of the presence of lettershapes in a corpus of 449 texts together with in-word position. The texts were all written in England and in less standardised orthography in the period c. 1350-1450. The specific modelling methodology-conditional inference treeswas preferred for its suitability with non-parametric data and its ability to avoid overfitting and biased predictor selection. Its application has been successful given the exploratory nature of the research and encourages the wider adoption of quantitative analytical methodologies for quantitative data in palaeography. Their adoption may increase definitional precision in palaeography and identify the best possible set of predictors.

The models have revealed the existence of a three-way north-south division of England, with certain Secretary letter-shapes especially prominent above the North Riding/County Durham line and certain other Secretary shapes especially prominent below the Midlands line, while Anglicana shapes dominate the area in between the two lines. The paper has suggested that this distribution is the result of letter-shapes hierarchically diffusing from the London-Westminster area to Durham institutions through the agency of clerks and the documents they processed. While this diffusion mechanism is well-documented at various levels of language, the prince-bishops of Durham and the associated institutions of county government have not received much attention in studies of the gradient between Anglicana and Secretary scripts. It is fruitful not only to look beyond royal clerks 
and Westminster and to clerks in general and the London-Westminster area when studying that gradient but also to look to the provinces.

Acknowledgment: The author acknowledges a residential fellowship at the Netherlands Institute for Advanced Study in the Humanities and Social Sciences. He thanks Laura Wright, Kari Anne Rand, Muriel Norde, and the anonymous reviewers for this journal for their helpful comments, and also Merja Stenroos for access to photographic reproductions of the texts examined. He read the paper at the workshop devoted to "The Emergence of Standard English in Multilingual Britain”, University of Cambridge, 20-21 April 2017.

\section{References}

Benskin, Michael. 1992. Some perspectives on the origin of standard written English. In Jan A. van Leuvensteijn \& Johannes B. Berns (eds.), Dialect and standard language in the English, Dutch, German and Norwegian language areas, 71-105. Amsterdam: Royal Netherlands Academy of Arts and Sciences.

Benskin, Michael. 2004. Chancery standard. In Christian Kay, Carole Hough \& Irene Wotherspoon (eds.), New perspectives on English historical linguistics. Vol. II: Lexis and transmission, 1-40. Amsterdam \& Philadelphia: John Benjamins.

Bischoff, Bernhard. 1979. Paläographie des römischen Altertums und des abendländischen Mittelalters. 1990. Latin palaeography: Antiquity and the Middle Ages. Transl. Dáibhí Ó Cróinín and David Ganz. Cambridge: Cambridge University Press.

Burgers, Jan. 2007. Palaeography and diplomatics: The script of charters in the Netherlands during the fourteenth and fifteenth centuries. Quaerendo 37. 1-23.

Chaplais, Pierre. 1971. English royal documents: King John-Henry VI 1199-1461. Oxford: Clarendon Press.

Clanchy, Michael T. 2013. From memory to written record: England 1066-1307, 3rd edn. Chicester: Wiley-Blackwell.

Derolez, Albert. 2003. The palaeography of Gothic manuscript books: From the twelfth to the early sixteenth century. Cambridge: Cambridge University Press.

Dodd, Gwilym. 2011a. The rise of English, the decline of French: Supplications to the English crown, c. 1420-1450. Speculum 86.117-150.

Dodd, Gwilym. 2011b. The spread of English in the records of central government, 1400-1430. In Elisabeth Salter \& Helen Wicker (eds.), Vernacularity in England and Wales, c.1300-1550, 225-266. Turnhout: Brepols.

Doyle, Anthony lan. 1994. A palaeographer's view. In Margaret Laing \& Keith Williamson (eds.), Speaking in our tongues: Medieval dialectology and related disciplines, 93-97. Cambridge: D. S. Brewer.

Ekwall, Eilert. 1956. Studies on the population of mediaeval London. Stockholm: Almqvist and Wiksell.

Fisher, John H. 1979. Chancery standard and modern written English. Journal of the Society of Archivists 6.136-144. 
Fisher, John H., Malcolm Richardson \& Jane L. Fisher. 1984. An anthology of Chancery English. Knoxville: University of Tennessee Press.

Friedman, John B. 1995. Northern English books, owners, and makers in the late Middle Ages. Syracuse: Syracuse University Press.

Hanna, Ralph. 2005. London literature, 1300-1380. Cambridge: Cambridge University Press. He, Sheng, Petros Samara, Jan Burgers \& Lambert Schomaker. 2014. Towards style-based dating of historical documents. In IEEE Computer Society (ed.), Proceedings: 14 th International Conference on Frontiers in Handwriting Recognition (ICFHR), 265-270. Los Alamitos: Conference Publishing Services.

Hothorn, Torsten, Kurt Hornik \& Achim Zeileis. 2006. Unbiased recursive partitioning: A conditional inference framework. Journal of computational and graphical statistics 15. 651-674.

Hothorn, Torsten \& Achim Zeileis. 2015. A toolkit for recursive partytioning. Version 1.0-5. https://cran.r-project.org/web/packages/partykit/partykit.pdf (accessed 16 April 2016).

Kwakkel, Erik. 2012. Biting, kissing and the treatment of feet: The transitional script of the long twelfth century. In Erik Kwakkel, Rosamund McKitterick \& Rodney Thomson (eds.), Turning over a new leaf: Change and development in the medieval book, 76-126 and 206-208. Leiden: Leiden University Press.

Kristensson, Gillis. 2001. Sociolects in fourteenth-century London. In Jacek Fisiak \& Peter Trudgill (eds.), East Anglian English, 71-77. Woodbridge: D.S. Brewer.

LALME = McIntosh, Angus, Michael Samuels \& Michael Benskin (eds.), with the assistance of Margaret Laing and Keith Williamson. 1986. A linguistic atlas of late mediaeval English. 4 vols. Aberdeen: Aberdeen University Press.

Matheson, Lister. 1986. Review of John H. Fisher, Malcolm Richardson \& Jane L. Fisher. 1984. Chancery English. (Knoxville: University of Tennessee Press). Speculum 61. 646-650.

McDermid, Richard T. W. 1980. The constitution and the clergy of Beverley minster in the Middle Ages. Durham: Durham University master's thesis.

MEG-C = Merja Stenroos, Martti Mäkinen, Simon Horobin \& Jeremy Smith (compilers). 2011. The Middle English Grammar Corpus, version 2011.1. Stavanger: University of Stavanger. www. uis. no/mest.

Mooney, Linne R. 2008. Locating scribal activity in late-medieval London. In Margaret Connolly \& Linne R. Mooney (eds.), Design and distribution of late medieval manuscripts in England, 183-204. York: York Medieval Press.

Parkes, Malcolm B. 1969. English cursive book hands, 1250-1500. Oxford: Oxford University Press.

Parkes, Malcolm B. 1973. The literacy of the laity. In David Daiches \& Linne R. Mooney (eds.), Literature and civilisation: The medieval world, 555-577. London: Aldus Books.

Parkes, Malcolm B. 2008. Their hands before our eyes: The Lyell lectures delivered at the University of Oxford, 1999. Aldershot: Ashgate.

Petti, Anthony G. 1977. English literary hands from Chaucer to Dryden. Cambridge: Harvard University Press.

Richardson, Malcolm. 2011. Middle-class writing in late medieval London. London: Pickering and Chatto.

Roberts, Jane. 2005. A guide to scripts used in English writings up to 1500. London: British Library Publications. 
Samara, Petros. 2015. Towards a medieval palaeographical scale (1300-1550). In Irmgard Fees, Benedikt Hotz \& Benjamin Schönfeld (eds.), Papsturkundenforschung zwischen internationaler Vernetzung und Digitalisierung: Neue Zugangsweisen zur europäischen Schriftgeschichte, n.p. Göttingen: Göttingen Academy of Sciences and Humanities. http: //hdl. handle. net/11858/00-001S-0000-0023-9A13-A

Samuels, Michael. 1963. Some applications of Middle English dialectology. English Studies 44. 81-94.

Takeda, Reiko. 2001. The question of the "standardisation" of written English in the fifteenth century. Leeds: University of Leeds doctoral thesis.

Thompson, John J. 2000. A poet's contacts with the great and the good: Further consideration of Thomas Hoccleve's texts and manuscripts. In Felicity Riddy (ed.), Prestige, authority, and power in late medieval manuscripts and texts, 77-101. York: York Medieval Press.

Wright, Laura. 1996. Sources of London English: Medieval Thames vocabulary. Oxford: Clarendon Press. 